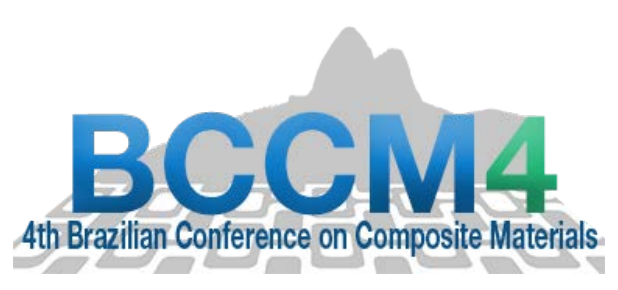

\title{
MULTIOBJECTIVE OPTIMIZATION OF COMPOSITE RISERS
}

\author{
Marina A. Maia ${ }^{(1)}$ and Evandro Parente Jr. ${ }^{(1)}$ \\ (1) Laboratório de Mecânica Computacional e Visualização, Universidade Federal do Ceará, \\ Fortaleza, Brazil.
}

https://doi.org/10.21452/bccm4.2018.16.08

\begin{abstract}
Use of fiber-reinforced laminated composites has proved itself as a valuable option in the manufacturing of risers, particularly for deepwater applications, a scenario where its lightweight related properties and good fatigue resistance are most needed. In addition, its use allows these structures to be tailored to meet specific manufacturing, safety, and stability criteria. This paper proposes an optimization model to composite risers in a free-hanging catenary configuration that considers multiple load cases and two objective functions. The optimization is carried out using a modified version of the Nondominated Sorting Genetic Algorithm II (NSGA-II). The riser structural analysis is performed by an inextensible cable model that accounts for the vertical static loads, floater offset and current loads in a fast and efficient way. The proposed algorithm is validated using a benchmark problem and applied to obtain the Pareto Front of a composite riser.
\end{abstract}

Keywords: Multiobjective optimization, Catenary risers, Composite materials.

\section{INTRODUCTION}

In the last few years, offshore projects have been set aside and onshore investments, particularly on tight oil, played a major role in the oil industry, forcing deepwater projects to be even more competitive. At the heart of this discussion are the risers, which work as a physical connection between the subsea wells and the floating production facility and are usually made of steel. An important alternative to help reduce cost is the replacement of steel risers by composite risers, especially in projects with water depths over $2000 \mathrm{~m}$, when the pipeline thickness increases significantly to sustain the higher hydrostatic pressure and the harsh environment and the weight reduction enabled by the composite use is most needed [1].

Composite materials have several others important advantages over metals (e.g. low thermal conductivity, good corrosion resistance and high specific strength and stiffness) and, more importantly, fiber-reinforced laminated composites allow risers to be tailored to meet specific manufacturing, safety, and stability constraints under several different loading conditions by choosing adequate design variables [2]. Using optimization technics in this type of problem could 
also enable the decision maker to consider features in the project that could be impracticable to do by trial and error, such as the consideration of multiple objective functions. It is important to note that the balance between better structural performance and cost has always been a major engineering concern.

This paper proposes a methodology to the multiobjective optimization of a composite catenary riser subjected to multiple load cases and constraints. A modified version of the Nondominated Sorting Genetic Algorithm II (NSGA-II), an algorithm proposed by [3] that proved itself as a useful tool for composite structures optimization $[4,5]$, is used for multiobjective optimization. The riser analysis is performed at two stages as suggests the global-local philosophy and the design variables considered are the ply thickness and fiber angle orientation.

\section{COMPOSITE CATENARY RISER}

The catenary (or free-hanging catenary) is one of the simplest configurations employed in deepwater offshore exploration and, basically, the riser rests on the seabed, which can significantly reduce the installation and operation costs due to minimal subsea equipment if compared to configurations that demand floating elements to shape their final forms (e.g. Lazy-S and LazyWave). Composite Catenary Risers (CCRs) generally consist of several segments assembled together by its connections, these segments are called joints and they are generally composed by outer and/or inner liner, the composite tube itself and terminations, properly connected to each other. In this work, connections and terminations are only accounted to the riser weight; any other contribution is not addressed since the major concern is to optimize the design of the composite tube. Typical positions of a CCR considering the floater offsets and the riser cross-section are depicted in Figure 1.

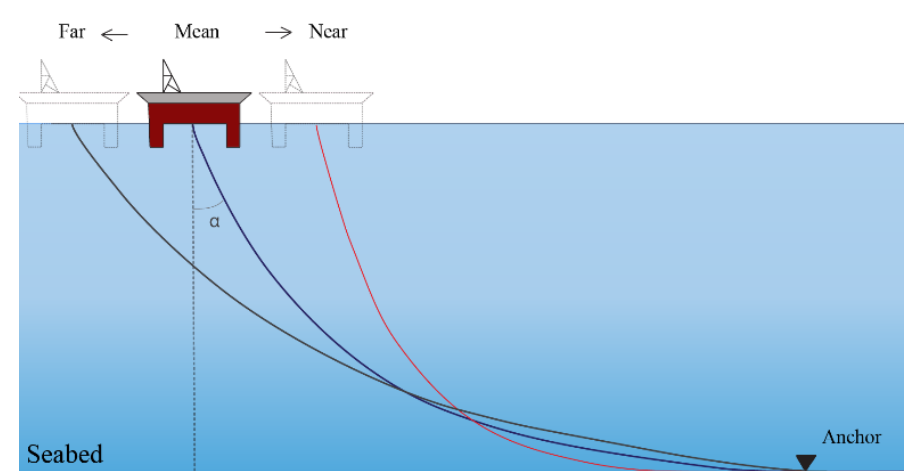

(a)

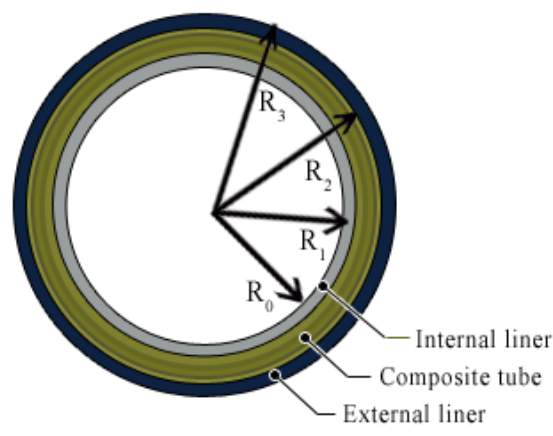

(b)

Figure 1 : (a) Catenary riser scheme (b) Composite riser cross-section

The riser structural analysis is performed in two stages, global and local, this methodology is employed to flexible risers, but also recommend to composite risers [6]. At the global step, an inextensible cable model [7] performs the analysis considering the entire riser system in order to obtain axial forces acting on it and global displacements (bending and torsional moments are neglected); these data are the input for the next stage of the analysis, when stresses and strains at each lamina are evaluated locally by the Classical Laminated Theory (CLT) in several sections of the riser. 


\subsection{Global Analysis}

In order to obtain the riser axial forces, the structure was assumed to behave as inextensible cable - that is, infinite axial stiffness and zero bending stiffness - subjected to vertical static loads (weight and buoyancy), horizontal (marine currents) and to the offset of the Floating Production Unit (FPU). The first step is to evaluate the dry weight, which consists of the sum of the riser components (internal liner, composite tube, external liner and terminations), next, the internal fluid per length unit $\left(w_{f l}\right)$ is calculated and added to the dry weight, while the buoyancy weight is subtracted from it, which leads to the effective weight per unit of the riser $\left(w_{e f}\right)$ [8].

\subsection{Local Analysis}

The CLT is employed to local analysis in several sections of the riser. At this point, internal liner and composite tube are considered as perfectly bound and, therefore, can be analysed as one single structural system, neglecting the external liner, which works only as a protective layer during transport and operation. The riser is subjected to the effective axial force (evaluated at the global analysis), internal and external pressure. Each layer thickness is represented by $h_{k}$ and the total thickness of the tube by $h_{t}$, the structure is, then, modelled as a cylindrical structure composed by $\mathrm{N}$ layers, where the first one corresponds to the internal liner and the rest of them to the layers of the composite tube, as shown in Figure 1 (b). To evaluate in-plane forces on the riser wall, the thin-walled tube theory is used, considering load factors recommended by $[6,9]$ :

$$
\begin{gathered}
N_{x}=\frac{N_{t w}}{2 \pi R}=\frac{\gamma_{F} N_{e f}^{M e a n}+\gamma_{E}\left(\beta N_{e f}-N_{e f}^{M e a n}\right)+\left(p_{i} \pi R_{0}^{2}-p_{e} \pi R_{2}^{2}\right)}{2 \pi R} \\
N_{y}=p_{i} R_{0}-p_{e} R_{2}
\end{gathered}
$$

where $N_{t w}$ is the true wall tension, $\mathrm{R}$ is the average radius of the structure composed by the composite tube and the internal liner, $\beta$ is the dynamic amplification factor, $\gamma_{F}$ is the functional load factor and $\gamma_{E}$ is the environmental load factor. In this work, $N_{x y}$ is taken as zero, once torsion is not considered, and hydrostatic pressures are computed from:

$$
\begin{aligned}
& p_{i}=p_{0}+\gamma_{f l} h \\
& p_{e}=\gamma_{w a t} h
\end{aligned}
$$

where $p_{0}$ is the pressure on the top of the riser, $h$ is the depth of the riser section where the forces are evaluated and $p_{i}$ and $p_{e}$ are the internal and external pressure, respectively.

\subsection{Failure Criteria}

To compute the composite safety factor, the First-Ply Failure methodology is applied. In this approach, the lowest safety factor evaluated for each layer $\left(S F_{k}\right)$, which is evaluated using TsaiWu criterion, is assumed to be the composite safety factor $\left(S F^{c}\right)$, that is, when the first layer fails, the whole structure supposedly fails too. This is a conservative approach, but simple and easy to implement and yield good results. The von Mises criterion is used to evaluate the internal liner resistance $\left(S F^{i l}\right)$.

\subsection{Buckling}

In order to assure the structural integrity of the riser, the structure is analysed considering the buckling due to external pressure. Collapse pressure of cylindrical orthotropic shells $\left(P_{c o l}\right)$ is 
estimated using the CLT and to evaluate the buckling safety factor ( $\mathrm{SF}^{\mathrm{bck}}$ ), collapse pressure is divided by the external pressure $\left(P_{e}\right)$, as shown in Eq. (3).

$$
\begin{gathered}
S F^{b c k}=\frac{P_{c o l}}{P_{e}} \\
P_{c o l}=k_{p} \frac{3}{R_{m}{ }^{3}}\left(D_{22}-\frac{B_{22}^{2}}{A_{22}}\right)
\end{gathered}
$$

where $k_{p}$ is the knock-down factor, a factor that aims to correct the difference between theory and empirical results and to long tubes is worth $0.75, R_{m}$ is the medium radius of the riser and $D_{22}, B_{22}$ and $A_{22}$ are coefficients obtained in the $\boldsymbol{A}, \boldsymbol{B}$ and $\boldsymbol{D}$ matrices given by the CLT. External pressure is evaluated at the touchdown point (TDP), point where the riser first touches the seabed, since this is where $P_{e}$ is maximum.

\section{DESIGN METHODOLOGY}

This section describes the main aspects considered to the composite riser design, starting on with the design variables, which consist of the thickness of each layer $\left(h_{k}\right)$ and the fiber orientation $\left(\theta_{k}\right)$. Thus:

$$
\mathrm{x}=\left\{\begin{array}{llllllllll}
\mathrm{h}_{1} \mathrm{~h}_{2} & \mathrm{~h}_{3} & \ldots & \mathrm{h}_{N_{p}} & \theta_{1} & \theta_{2} & \theta_{3} & \ldots & \theta_{N_{p}}
\end{array}\right\}^{t}
$$

where $N_{p}$ is the maximum number of plies. By imposition, the stacking sequence is the same for all sections of the riser. Typically, thickness and fiber orientations are characterized as discrete variables, since their allowable values belong to a finite set of values due to manufacturing constraints.

The composite tube thickness minimization and buckling safety factor maximization are the criteria selected for the optimization. It is important to notice that, as the stacking sequence is constant and only one material was used, minimization of the composite tube thickness corresponds to the minimization of its cost. Constraints considered in present work are either related to the strength of the composite material and liner or related to the riser stability. Having that in mind, $S F_{i j}^{l}$ and $S F_{i j}^{c}$ correspond to the safety factors of the liner and the composite evaluated for load case $i$ at section $j$ of the riser and $S F_{r e q}^{l}$ and $S F_{r e q}^{c}$ are the required safety factors to the liner and the composite tube according to [6], respectively. That way, safety requirements of resistance are guaranteed if the following relations are assured:

$$
\begin{aligned}
& g_{i j}^{l}(x)=\frac{S F_{r e q}^{l}}{S F_{i j}^{l}}-1 \leq 0 \\
& g_{i j}^{c}(x)=\frac{S F_{r e q}^{c}}{S F_{i j}^{c}}-1 \leq 0
\end{aligned}
$$

where $i=1,2,3, \ldots, N_{l c}, j=1,2,3, \ldots, N_{v s}, N_{v s}$ is the number of sections considered in the riser and $N_{l c}$ is the number of load cases considered. In this work, the buckling safety factor $\left(S F^{b c k}\right)$ is evaluated at the worst scenario, which corresponds to the empty riser at the TDP and neglecting the resistance of the internal liner. This factor is compared to the required buckling safety factor $\left(S F_{\text {req }}^{\text {bck }}\right)$.

The riser is subjected to internal and external pressure, floater offsets and marine currents. Table 1 summarizes the load cases selected to the numerical example shown later on. It is worth noting 
that waves are not considered since this would require dynamic analysis that could significantly increase computational cost and present work aims to present a simple and efficient optimization methodology for the preliminary design of composite risers.

Table 1 : Load cases

\begin{tabular}{ccccccc}
\hline & $\begin{array}{c}\text { Offset } \\
\text { (\% of WD) }\end{array}$ & Position & $\begin{array}{c}\text { Fluid } \\
\text { density } \\
\left(\mathrm{kg} / \mathrm{m}^{3}\right)\end{array}$ & $\begin{array}{c}\text { Pressure } \\
\text { on top } \\
(\mathrm{MPa})\end{array}$ & \multicolumn{2}{c}{ Marine current profile } \\
\cline { 5 - 7 } & $\Delta_{\text {os }}$ & & $\rho_{f l}$ & $p_{0}$ & $\begin{array}{c}\text { Vertical } \\
\text { coordinates } \\
(\mathrm{m})\end{array}$ & $\begin{array}{c}\text { Current } \\
\text { velocity } \\
(\mathrm{m} / \mathrm{s})\end{array}$ \\
\hline Max. production & 8.5 & Far & 880.0 & 30.0 & $(0 ; \mathrm{WD})$ & $(0 ; 1.0)$ \\
Max. production & 8.5 & Near & 880.0 & 30.0 & $(0 ; \mathrm{WD})$ & $(0 ;-1.0)$ \\
Empty riser & 8.5 & Far & 0.0 & 0.0 & $(0 ; \mathrm{WD})$ & $(0 ; 1.0)$ \\
Empty riser & 8.5 & Near & 0.0 & 0.0 & $(0 ; \mathrm{WD})$ & $(0 ;-1.0)$ \\
Hydrotest & 3.0 & Far & 1006.0 & 37.5 & $(0 ; \mathrm{WD})$ & $(0 ; 0.30)$ \\
Hydrotest & 3.0 & Near & 1006.0 & 37.5 & $(0 ; \mathrm{WD})$ & $(0 ;-0.30)$ \\
\hline
\end{tabular}

WD: Water depth.

The NSGA-II is as a fast and elitist multiobjective optimization algorithm that evolves its population of solutions through many processes of sorting [3]. The main modifications made in this work are related to how the algorithm deals with composite laminated problems, especially when it comes to the encoding of the variables and specific operators. Here, the encoding of the design variables is made using a correspondence of the $n$ allowable thickness values to a list of numbers from 1 to $n$, in which each value of that list corresponds to a design variable, the same process is done to the fiber orientation. This is especially useful for the algorithm operations such as crossover and mutation. Another important feature implemented, particularly for hybrid composite laminated problems, is the modification of a small number of solutions (randomly selected) in a way that these solutions are modified to be composed by only one material, which could take many generations for the algorithm to generate by itself. Computational implementation was done in an in-house software written in $\mathrm{C}++$.

\section{NUMERICAL EXAMPLES}

In order to validate the algorithm implementation, a benchmark named TNK is selected. Once this verification is done, a numerical example of a CCR is illustrated.

\subsection{Validation}

The benchmark objective functions are $f_{1}=x_{1}$ and $f_{2}(x)=x_{2}$, the two continuous variables have bounds $[0, \pi]$ and two constraints, $g_{1}(x)=-x_{1}^{2}-x_{2}^{2}+1+0.1 \cos \left[16 \arctan \left(\frac{x_{1}}{x_{2}}\right)\right] \leq 0$ and $g_{2}(x)=\left(x_{1}-0.5\right)^{2}+\left(x_{2}-0.5\right)^{2} \leq 0.5$. The number of optimizations, population size, mutation probability, crossover rate and the maximum number of generations were set as 10, 100, 5\%, 100\% and 500, respectively. Results are presented in Figure 2. 
$4^{\text {th }}$ Brazilian Conference on Composite Materials. Rio de Janeiro, July $22^{\text {nd }}-25^{\text {th }}, 2018$

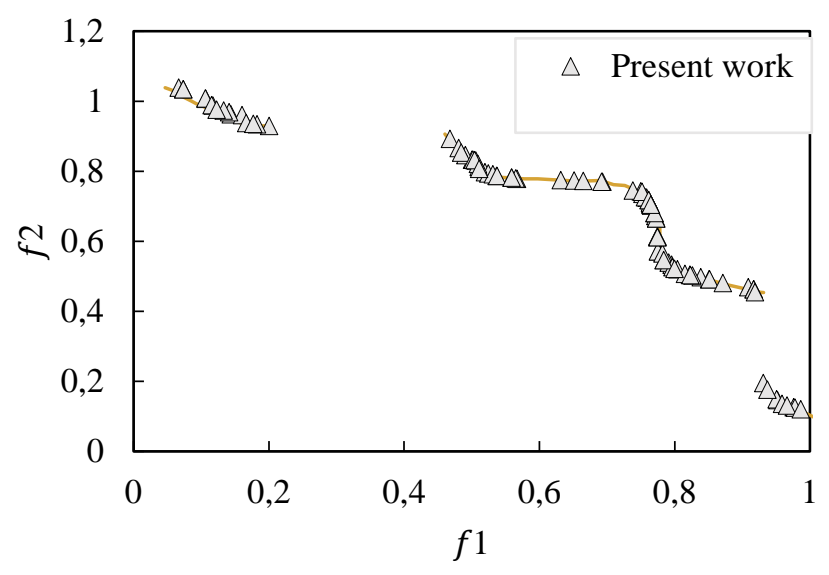

Figure 2 :Results for TNK problem

Results show great agreement between the Pareto Front found by [3] and present work, proving the good functioning of the algorithm.

\subsection{Composite catenary riser}

In this example, water depth is considered as $1500 \mathrm{~m}$, riser length is taken as $4500 \mathrm{~m}$, the internal liner has $0.125 \mathrm{~m}$ of thickness, top angle $(\alpha)$ is $17^{\circ}$ and the maximum number of plies is 30. The thicknesses of the internal and external liner are set as 0.005 and $0.003 \mathrm{~m}$, respectively. Terminations are taken as $5 \%$ of the joint length and are made of steel. When it comes to the load factors, the following values for the functioning load factor $\left(\gamma_{F}\right)$, environmental load factor $\left(\gamma_{E}\right)$ and amplification factor $(\beta)$ were considered: 1.1, 1.3 and 1.5. Required SFs considering [6, 9] were found to be: 1.3 for the internal liner $\left(S F_{r e q}^{i l}\right), 2.1$ for the composite tube $\left(S F_{r e q}^{c}\right)$ and 3.0 for the buckling $\left(S F_{r e q}^{b c k}\right)$. The drag coefficient is set as 1.0 and load cases presented previously on the design methodology section are used. The properties of the composite material $\left(\gamma_{\text {comp }}=15.69\right.$ $\mathrm{kN} / \mathrm{m}^{3}$ ) are shown in Table 3, degraded properties, that is, when the matrix of the composite material is considered as failed, were evaluated according to [9], the FPF analysis, then, becomes equivalent to a First-Fiber Failure (FFF) analysis, once fibers are the only ones resisting. To the internal liner manufacturing steel API X65 was selected, which has a yield stress of $203 \mathrm{MPa}$ and Poisson's coefficient of 0.3 , for the external liner a polymeric material of weight $9.04 \mathrm{kN} / \mathrm{m}^{3}$ was used.

Table 2 : Composite material properties

\begin{tabular}{ccccccccccc}
\hline $\begin{array}{c}\boldsymbol{E}_{\mathbf{1}} \\
(\mathrm{GPa})\end{array}$ & $\begin{array}{c}E_{2} \\
(\mathrm{GPa})\end{array}$ & $\begin{array}{c}\boldsymbol{G}_{\mathbf{1 2}} \\
(\mathrm{GPa})\end{array}$ & $\vartheta$ & $\begin{array}{c}F_{1 t} \\
(\mathrm{MPa})\end{array}$ & $\begin{array}{c}F_{1 c} \\
(\mathrm{MPa})\end{array}$ & $\begin{array}{c}\boldsymbol{F}_{\mathbf{2 t}} \\
(\mathrm{MPa})\end{array}$ & $\begin{array}{c}F_{2 c} \\
(\mathrm{MPa})\end{array}$ & $\begin{array}{c}\boldsymbol{F}_{\mathbf{3} \boldsymbol{t}} \\
(\mathrm{MPa})\end{array}$ & $\begin{array}{c}\boldsymbol{F}_{\mathbf{3} \boldsymbol{c}} \\
(\mathrm{MPa})\end{array}$ & $\begin{array}{c}\mathrm{S} \\
(\mathrm{MPa})\end{array}$ \\
\hline 135.00 & 10.00 & 5.00 & 0.30 & 1500.00 & 1200.00 & 50.00 & 250.00 & 50.00 & 250.00 & 70.00 \\
\hline
\end{tabular}

The following algorithm parameters were set: 100 generations, 100 individuals, 5\% of probability of mutation, $100 \%$ of crossover rate and 3 optimizations. The allowable values for ply thickness vary from $1 \mathrm{~mm}$ to $5 \mathrm{~mm}$ in steps of $1 \mathrm{~mm}$, while the allowable angles vary from $0^{\circ}$ to $90^{\circ}$ in steps of $5^{\circ}$. Only symmetrical and balanced lay-ups are allowed. Results are shown in Figure 4, followed by Table 3, which presents one stacking sequence for each curve. 


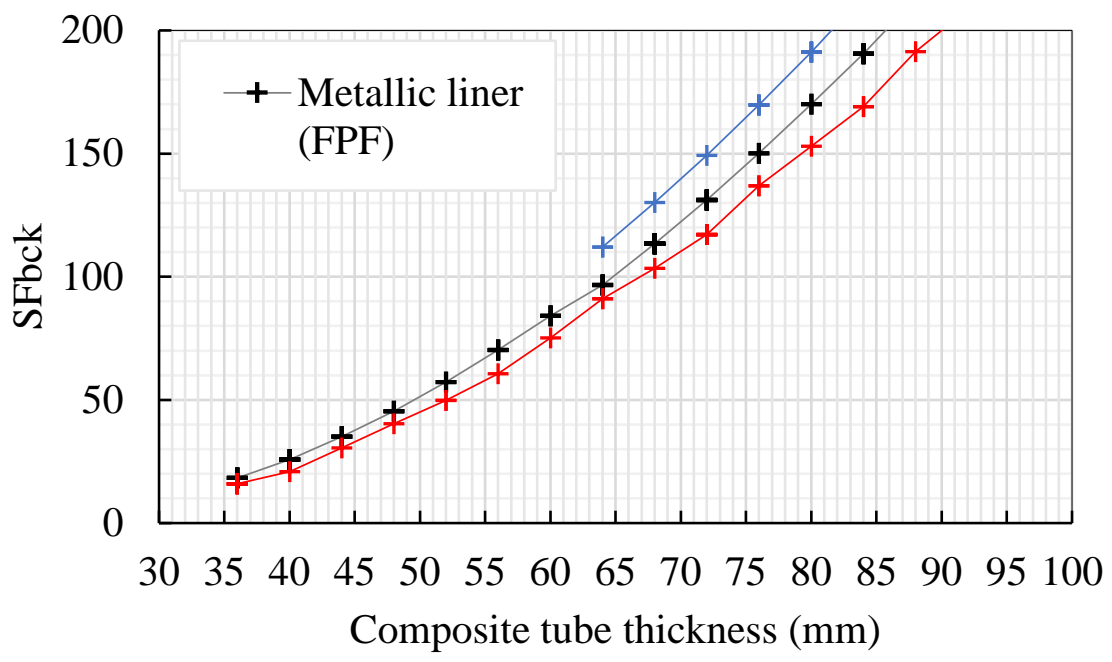

Figure 3 : Nondominated solutions for different combinations of liner and composite material

Table 3 : Lay-ups for different combinations of liner and composite material

\begin{tabular}{|c|c|c|c|c|c|c|}
\hline \multirow[t]{2}{*}{ Liner/Composite } & & \multirow[t]{2}{*}{ Lay-up } & \multicolumn{2}{|c|}{ Constraints } & \multicolumn{2}{|c|}{$\begin{array}{l}\text { Objective } \\
\text { functions }\end{array}$} \\
\hline & & & $S F^{i l}$ & $S F^{c}$ & $S F^{b c k}$ & $h_{t}$ \\
\hline $\begin{array}{l}\text { Metallic/Intact } \\
\text { (FPF) }\end{array}$ & $\begin{array}{l}\mathrm{h}(\mathrm{mm}) \\
\boldsymbol{\theta}\left({ }^{\circ}\right)\end{array}$ & $\begin{array}{c}{[1,1,1,1,1,1,1,1,1,1,2,2,2,2] \mathrm{s}} \\
{\left[ \pm 85, \pm 80, \pm 65_{2}, \pm 15, \pm 20_{2}\right] \mathrm{s}}\end{array}$ & 1.37 & 2.33 & 18.31 & 36 \\
\hline $\begin{array}{l}\text { Metallic/Degraded } \\
\text { (FFF) }\end{array}$ & $\begin{array}{l}\mathrm{h}(\mathrm{mm}) \\
\boldsymbol{\theta}\left({ }^{\circ}\right)\end{array}$ & $\begin{array}{l}{[1,1,1,1,1,1,2,2,1,1,2,2,1,1] \mathrm{s}} \\
{[ \pm 75, \pm 85, \pm 80, \pm 10, \pm 55, \pm 15] \mathrm{s}}\end{array}$ & 1.30 & 4.67 & 16.61 & 36 \\
\hline $\begin{array}{l}\text { No liner/Intact } \\
\text { (FPF) }\end{array}$ & $\begin{array}{c}\mathrm{h}(\mathrm{mm}) \\
\boldsymbol{\theta}\left(^{\circ}\right)\end{array}$ & $\begin{array}{c}{[4,4,3,3,2,2,1,1,1,1,4,4,1,1] \mathrm{s}} \\
{\left[ \pm 85_{5}, \pm 15_{2}\right] \mathrm{s}}\end{array}$ & - & 2.29 & 112.04 & 64 \\
\hline
\end{tabular}

It can be seen that the consideration of the matrix failure does not directly affect the composite tube thickness optimization when the liner is considered in the project. However, different stacking sequences for the same tube thickness do change the buckling safety factor. Naturally, when the composite is considered intact, SFs were higher. When no internal liner was considered, the composite tube was $78 \%$ thicker and presented a much higher $S F^{b c k}$. However, this is a tricky conclusion, once the global cost of the structure considering its assemble and manufacturing cost may increase with the use of an internal liner.

\section{CONCLUSION}

The main purpose of this work is to present a methodology to the multiobjective optimization of catenary risers, which is a powerful tool to help the decision maker choose between solutions obtained from criteria that are often a trade-off. A benchmark from the literature was used to validate the algorithm. In the numerical example of a composite riser, solutions obtained showed that either FPF or FFF analysis led to the same minimum composite tube thickness when the 
$4^{\text {th }}$ Brazilian Conference on Composite Materials. Rio de Janeiro, July $22^{\text {nd }}-25^{\text {th }}, 2018$

internal liner is considered (although with different safety factors). On the other hand, the absence of such component showed a high impact on the chosen optimization criteria. Finally, it is important to highlight that the objective functions can be easily modified in order to represent other criteria that need to be optimized.

\section{ACKNOWLEDGEMENTS}

The financial support by CNPq (Conselho Nacional de Desenvolvimento Científico e Tecnológico) and FUNCAP (Fundação Cearense de Apoio ao Desenvolvimento Científico e Tecnológico) are gratefully acknowledged.

\section{REFERENCES}

[1] U.S. Energy Information Administration, 'Trends in U.S. Oil and Natural Gas Upstream Costs', Report, March, 2016.

[1] Ochoa, O. O., 'Composite Riser Experience and Design Guidance', Offshore Technology Research Center Library, Technical Report, Texas, 2006.

[2] Deb, K., Pratap, A., Agarwal, S. and Meyarivan T., 'A Fast and Elitist Multiobjective Genetic Algorithm', IEEE Transactions on Evolutionary Computation. 6 (2) (2002) 182-197.

[3] Kalantari, M., Dong, C. and Davies, I. J., 'Multi-objective robust optimisation of unidirectional carbon/glass fibre reinforced hybrid composites under flexural loading', Composite Structures. 138 (2016) 264-275.

[4] Vo-duy, T., Duong-gia, D., Ho-huu, V., Vu-do, H. C. and Nguyen-thoi, T., 'Multi-objective Optimization of Laminated Composite Beam Structures Using NSGA-II Algorithm', Composite Structures. 168 (2017) 498-509.

[5] Det Norske Veritas, ‘DNV-RP-F202 Composite Risers’, October, 2010.

[6] Alves, J. C., Parente Junior, E., 'Análise numérica de risers utilizando um modelo de cabo inextensível' in Iberian Latin American Congress on Computational Methods in Engineering, Brasília, Brazil, 2016.

[7] Silva, R. F., Teófilo, F. A. F., Parente Junior, E., Melo and A. M. C., Holanda, A. S., 'Optimization of composite catenary risers', Marine Structures. 33 (2013) 1-20.

[8] Det Norske Veritas, 'DNV-OS-C501 Composite Components', November, 2013. 